\title{
ASSISTÊNCIA DE ENFERMAGEM AO INDIVÍDUO COM AFECÇÃO NEUROLÓGICA
}

\author{
Eliane Corrêa Chaves*
}

CHAVES, E.C. Assistência de enfermagem ao individuo com afecção neurológica. Rev. Esc. Enf. USP, São Paulo, 22(3): 283-288, dez. 1988.

A resposta do sistema nervoso às alteraçóes patológicas na sua estrutura anátomo-funcional podem ocasionar desequilíbrios na vida de relação de suas vítimas, gerando problemas de ordem psico-sóciobiológicas. Estes problemas afetam algumas necessidades básicas desses individuos destacando-se, entre elas, motilidade, locomoçäo, exercício, atividade física, integridade cutâneo mucosa, oxigenação, nutriçâo, hidratação e eliminação. A enfermeira deve estar atenta e apta para responder estas e outras necessidades que estes pacientes possam apresentar.

UNITERMOS: Assistência de enfermagem. Enfermagem Neurológica.

\section{INTRODUÇÃO}

Apesar de acreditarmos que todo ser humano deve ser visto e assistido como alguém com características próprias e distintas, as quais devem ser respeitadas e consideradas em quaisquer circunstância, entendemos que, diante de certas situaçōes de desequilibrio no seu estado saúde-doença, alguns sinais e sintomas, algumas respostas físicas e até mesmo emocionais podem ser semelhantes entre aqueles afetados por agravos da mesma natureza, podendo, inclusive, necessitar de assistência similar.

Nesse sentido, parece-nos procedente considerar que algumas situaçðes problemáticas, comuns a grande número de individuos com afecçðes neurológicas e as condutas adotadas pela enfermeira no sentido de evitá-las, resolvê-las ou minimizá-las sejam discutidas e analisadas. Desta forma, pretendemos contribuir para o aprimoramento da assistência a estes pacientes, desde que o respeito à sua individualidade continue sendo o objetivo maior dessa assistência.

A estrutura anátomo fisiológica do sistema nervoso tem características que valorizam a localização e a extensão da afecção, tanto quanto a sua própria natureza. Não é infreqüente, portanto, que a conduta inicial na assistência de enfermagem baseia-se unicamente nos sinais e sintomas determinados pela localização e extensão do agravo, mesmo que sua natureza seja ainda desconhecida.

Fundamentada nesta estrutura singular do sistema nervoso, MITCHELL'2 apresenta quatro princípios que norteiam a compreensão da problemática do paciente com afecçðes cerebrais, medulares e até mesmo de nervos periféricos. São eles:

- Enfermeira. Mestre em Enfermagem. Professor Assistente do Departamento de Enfermagem Médico-Cirúrgica da Escola de Enfermagem da USP - disciplina Enfermagen: Méúicu-Cirúrgica. 
- O sistema nervoso central é um sistema de condução elétrica. Qualquer bloqueio nesta condução resultará em disfunção distal à quebra. O tipo e o grau da disfunção dependem da localização, natureza e extensão da lesão;

- O sistema nervoso central é um sistema fechado, com pequena capacidade de expansão; um aumento de pressão não aliviado poderá, eventualmente, ser transmitido no sentido descendente;

- As células do sistema nervoso central podem recuperar sua função, mesmo após edema considerável, se a morte celular não ocorreu, mas a célula morta não se recupera. Apenas os axônios mielinizados dos nervos periféricos podem se regenerar.

- As reaçð̃es do indivíduo à disfunção neurológica dependem do seu padrão individual de reação ao estresse, da extensão, localização e natureza da lesão e dos efeitos da disfunção na sua auto-imagem.

A partir destes quatro princípios e de conhecimentos básicos da anatomia e fisiologia do sistema nervoso, torna-se evidente que as disfunçðes mais freqüentes encontradas nos indivíduos com afecções neurológicas são as de ordem motora, sensitiva e de nível de consciência. Estas disfunçðes, por sua vez, alteram a relação de suas vítimas consigo mesmas e com o meio ambiente, em diferentes graus de intensidade, mas na grande maioria das vezes acarretam problemas de ordem psico-sóciobiológica.

Não perceber, não reagir ao meio resulta fatalmente em desequilíbrio de algumas necessidades básicas do individuo, dentre as quais destacam-se motilidade, locomoção, exercício e atividade física. Além destas, outras poderão entrar em desequilíbrio por estarem intimamente relacionadas as primeiras, como a integridade cutâneo-mucosa, oxigenação, nutrição, hidratação e eliminação.

O desequilíbrio destas necessidades se manifestará através de problemas de pele, músculos, nutrição, hidratação, eliminação intestinal e urinária, respiração e circulação.

\section{PROBLEMAS DA PELE}

A circulação no tecido denervado é pobre por causa da diminuição da atividade muscular. A presença deste estado patológico associado às alteraçð̄es físiológicas, também decorrentes da imobilização prolongada, explica a diminuição da resistência tecidual em pacientes portadores de déficit motor e sensitivo. Os movimentos normais que protegem a pele da pressão estão ausentes. Com frequêencia, áreas de pressão resultam em local de isquemia causada pela compressão de partes moles. Células destes tecidos morrem porque os nutrientes não conseguem atingí-las pelos capilares e os restos metabólicos não são eliminados ${ }^{(2)}$. Essa deficiência circulatória ocorre porque a pressão externa sobre o tecido é maior que a pressão hidrostática dentro dos capilares; portanto, a pressão exercida sobre a pele e tecido subcutâneo de uma determinada região é o maior fator de formação e desenvolvimento de úlceras de decúbito. A escarificação da pele ocorre com maior freqüência em proeminências ósseas. A proteína endógena pode ser perdida como resultado do catabolis- 
mo proveniente das ulceraçðes da pele e (ainda decorrente) do balanço nitrogenado negativo que se estabelece. A vulnerabilidade à formação de escaras aumenta devido à hipoproteinemia e até à anemia. A correção do estado nutricional nestes pacientes é de suma importância.

A inspeção freqüente da superfície corpórea é importante para detecção precoce de alteraçð̃es da pele, assim como higiene, mudança de decúbito freqüente e ativação da circulação. Exercícios de movimentação devem ser feitos várias vezes ao dia, desde que não haja contra-indicação, numa tentativa de melhorar a circulação sanguinea, evitar contraçð̃es e atrofias de grupos musculares. As deficiências circulatórias precisam ser consideradas nos casos em que é empregada medicação intramuscular; esta, sempre que possivel, deve ser administrada em regiðes não comprometidas para garantir absorção eficaz ${ }^{(3)}$.

\section{PROBLEMAS DE NUTRIÇÃO E HIDRATAÇÃO}

A anorexia, comum em pessoas imobilizadas por longo tempo, pode ser decorrente, entre outros fatores, da inatividade e dos aborrecimentos ou preocupaçðes do indivíduo ${ }^{(1)}$.

A atonia gástrica, comumente encontrada, retarda o esvaziamento gástrico, resultando em sensação de empachamento e distensão abdominal, o que acentua a perda de apetite ${ }^{(1)}$.

Esses dois fatores contribuem para tornar negativo o balanço nitrogenado, devido à diminuição da ingestão proteica. Os tecidos são catabolizados, a proteína é rapidamente excretada através da urina e grande quantidade de nitrogênio e potássio é perdida. Neste período, a alimentação forçada é condenada pois poderá provocar náuseas e vômitos, o que resultará em desequilíbrio eletrolítico.

A perda de proteínas após certo período de tempo pode determinar estados de desnutrição, perda de peso, predisposição a infecçðes e diminuição da resistência tecidual à pressão, o que predispðe à formação de úlcera de decúbito; portanto, o acréscimo da quantidade de proteínas, calorias e vitaminas na dieta destes pacientes é de vital importância na prevenção deste estado de carência nutricional.

A administração de líquidos também merece atenção especial, pois visa hidratação adequada e manutenção de função urinária satisfatória.

O balanço negativo de cálcio também ocorre em consequiência da imobilização, e sua perda em quantidade considerável pode resultar em osteoporose, decorrente da mobilização do cálcio ósseo para o sangue. A presença de cálcio nos rins e na urina torna possível a formação de cálculos no trato urinário.

O cálcio, normalmente, está presente na urina e é eliminado sem qualquer problema a partir de volume urinário e pH adequados. Se o aumento na excreção de cálcio durante a imobilização não for acompanhado de aumento proporcionado por outros fatores, podem ocorrer problemas de precipitaţão do mesmo.

A enfermeira pode prevenir essa conseqüência ofertando líquidos ao paciente. mais freqüentemente, a fim de promover o aumento do volume urinário e estimular a ingestão de cereais, carnes e outros alimentos que resultem em resíduos ácidos. 


\section{PROBLEMAS DE ELIMINAÇAŌ}

Entre as alteraçðes patológicas que freqüentemente ocorrem em pessoas imobilizadas estão os cálculos renais, infecção urinária, bexiga neurogênica e obstipação intestinal.

Dentre elas, a bexiga neurogênica, sem dúvida nenhuma, é a mais difícil de ser combatida. A assistência de enfermagem ao paciente com esta disfunção deve estar baseada em orientação de especialistas que avaliem o tipo de bexiga neurogênica, o grau de disfunção vesical e a recuperação possível de ser obtida. Apesar disto, acreditamos que é dever da enfermeira conhecer fisiopatologicamente as disfunçð̃es urinárias que podem advir de determinada afecção neurológica, para que ela possa acompanhar e avaliar a evolução do estado de seu paciente. Dada a extensão e complexidade do assunto, no entanto, não nos parece procedente apresentá-lo aqui, mesmo porque fugiria do objetivo do presente trabalho. Neste sentido, pode ser lembrado que, seja qual for o tipo de bexiga neurogênica e da afeç̧ão neurológica que a gerou, espera-se que o paciente consiga tornar sua eliminação urinária o mais próxima possivel da fisiológica e, para isso, além da conduta específica que será indicada pelo urologista, caberá à enfermeira manter a bexiga livre de outras complicaçðes que retardariam sua reabilitação. Estas complicaçðes são principalmente o aparecimento de infecçðes urinárias, de cálculos e da degeneração da parede vesical e conseqüentemente de seus plexos nervosos intramurais, devido à constante pressão exercida sobre eles por acúmulo de tíquido.

A distensão vesical prolongada e exagerada deve, portanto, ser evitada para preservar a integridade da musculatura vesical, prevenir infecçð̄es urinárias decorrentes de estase urinária ou, ainda, afecçðes renais devidas à pressão retrógrada exercida pela urina.

Nesse sentido, a sondagem vesical é freqüentemente necessária, principalmente na fase inicial da assistência. A técnica asséptica no manuseio e manutenção desse sistema de drenagem e a observação das características e volume do material drenado são fatores importantes na prevenção de complicaçðes urinárias.

Atenção especial também deve ser dada à dieta e a hidratação. Visando diluir a urina, evitar deposição de cálcio e manter o pH urinário adequado, o indivíduo deve ingerir grande quantidade de líquido, principalmente suco de frutas cítricas, que possam contribuir para a diminuiçăo do $\mathrm{pH}$ da urina, tornando-a menos susceptivel ao desenvolvimento de bactérias.

A obstipação intestinal também é um problema que aparece com grande freqüência em pacientes imobilizados. É decorrente de uma série de fatores entre os quais o fato do indivíduo estar, na maioria das vezes, com a força da musculatura abdominal e perineal comprometidas, ou de assumir posição inadequada durante a utilização da conadre, a qual não favorece a expulsão das fezes, ou, ainda, pelo fato de evacuar numa enfermaria, na presença de outros pacientes, onde mesmo que haja privacidade visual, não haverá maneira de ocultar dores e ruidos provenientes dos movimentos intestinais, o que, obviamente, constrangirá o indivíduo.

Como resultado desses fatores, a obstipação aparece e se agrava dia a dia; quanto mais tempo as fezes permanecerem no colon intestinal, mais a água é absorvida nesse nível, dificultando sobremaneira a evacuação. 
A enfermeira deve ter o objetivo de ajudar o paciente a criar um novo hábito intestinal; para isso ela procura providenciar, de forma sistemática, no horário que o paciente julgar mais conveniente, a adequação do ambiente, tanto quanto possivel, e orientá-lo a adotar posição física que facilite a expulsão das fezes. Deve estar atenta à frequência das evacuaçðes, à hidratação adequada, à dieta rica em resíduos, à movimentação do paciente e às massagens abdominais. Tais medidas visam evitar a utilização de laxantes que, na grande maioria, apenas retardam a reeducação intestinal.

\section{PROBLEMAS RESPIRATÓRIOS}

Problemas respiratórios, tão comuns em qualquer paciente acamado, tornam-se ainda mais perigosos nos indivíduos portadores de lesão cervical, nos quais a imobilização é completa, e em pacientes com fratura de coluna lombar, onde o indivíduo é mantido em decúbito dorsal horizontal(3).

Normalmente os pacientes imobilizados apresentam diminuição da força dos músculos respiratórios, o que leva a diminuição da expansibilidade torácica. A pressão da cama contra o tórax também contribui para a diminuição desta expansibilidade, predispondo o paciente à respiração superficial. Todos esses fatores causam estase das secreçðes normais dos pulmðes, propiciando um meio adequado para o desenvolvimento de bactérias, ou seja, para a instalação de um quadro pneumônico(2).

Esse tipo de pneumonia favorecida pela estase de secreçðes, precisa ser evitado por meio de movimentação destas secreçðes. Para tal, a enfermeira deve orientar o paciente a utilizar sistematicamente da respiração profunda e da tosse e deve providenciar mudança de decúbito na programação da assistência ao seu paciente imobilizado.

\section{PROBLEMAS CIRCULATÓRIOS}

A imobilidade prolongada pode alterar a fisiologia circulatória de várias maneiras. Uma das alteraçðes mais freqüentes e mais importante a que estão sujeitos os pacientes imobilizados é a sucetibilidade à formação de trombos e êmbolos.

Três fatores associados são responsáveis pelo tromboembolismo em indivíduos imobilizados: hipercoagulabilidade sanguínea, trauma e infeç̧ão na parede dos vasos e estase-circulatória (2). Há evidência de que a estase "de per si" não é causa de trombose, mas de qualquer maneira, potencializa a ação dos outros dois fatores.

As medidas de enfermagem preventiva devem ter como objetivo evitar a estase circulatória e os danos venosos traumáticos, principalmente nos membros inferiores.

A maioria dos pacientes com afecçð̃es neurológicas é parcial ou totalmente dependente da enfermagem, portanto dela depende a prevenção de compliçaçðes decorrentes de disfunçðes.

Muitas vezes, os déficits físicos são de caráter irreversível e podem ocasionar sentimentos de frustração, tanto para o paciente como para a equipe de enfermagem. Cabe lembrar, no entanto, que embora o objetivo da assistência de enferma- 
gem vise a cura do paciente, muitas vezes ele não é possível de ser atingida. Nestes casos, a meta deve ser a prevenção de complicações, a manutenção das funções físiológicas em níveis de normalidade e a adaptação de indivíduo à sua nova condição, conseguida através de autonomia em seu autocuidado e aceitação da sua auto imagem, mesmo que isso só venha a ocorrer a longo prazo(1).

É importante lembrar, ainda, que a reabilitação terá melhores resultados quando iniciada precocemente, e que cabe à enfermeira hospitalar, se não iniciá-la, pelo menos manter as condições físicas e emocionais do paciente necessárias para facilitála e não retardá-la.

A enfermeira deve conhecer as alteraçðes que podem ocorrer em seu paciente para poder agir corretamente, pois grande parte da assistência de enfermagem baseia-se em óbservação constante e avaliação correta(1).

ZHAVES, E.C. Nursing care of neurological patients. Rev. Esc. Enf. USP, São Paulo, 22(3): 283288, Dec. 1988.

The disease of the neurological estructure may cause biological, psychological, sociological and economical troubles. Among this problems we can mention, for example, the degeneration of the movement, of the fisical action, of the skin integrity, of the oxigenation, of the nutrition and of the urinary and intestinal elimination. The nurses need to be alert and able to attend this kind of patients, decreasing the necessities that they probably have.

UNITERMS: Nursing care. Neurologic Nursing.

\section{REFERÊNCIAS BIBLIOGRÁFICAS}

1. KOIZUMI, M.S. O paciente com afecções medulares. São Paulo, 1978. p.48-55. (mimeografado).

2. MITCHELL, P.H. Motor status In:

Concepts basic to nursing. New York, McGraw Hill Book, 1973. p.220-69.

3. MOIDEL, H.C. et alii. The patient with disease of the nervous systen. In: Nursing care of patient with medical - surgical disorders. New York, MacGraw Hill Book, 1971. p.977-1072. 